\title{
MAKNA IMPERATIF STRUKTURAL DAN NONSTRUKTURAL DALAM NOVEL ANAK BERBAHASA INGGRIS HELLO UNIVERSE KARYA ERIN ENTRADA KELLY
}

\author{
Afni Apriliyanti Devita ${ }^{* 1}$, Wahya $^{2}$, Nani Darmayanti ${ }^{3}$ \\ 1,2,3 Universitas Padjadjaran \\ JIn. Raya Bandung Sumedang KM. 21 Hegarmanah, Kec. Jatinangor, Kabupaten \\ Sumedang, Jawa Barat, 45363, Indonesia \\ Email: Afni19001@mail.unpad.ac.id ${ }^{* 1}$,wahya@unpad.ac.id ${ }^{2}$, n.darmayanti@unpad.ac.id ${ }^{3}$
}

\begin{abstract}
Abstrak
Salah satu karya sastra untuk anak yang dapat dijadikan sebagai media pembelajaran bahasa Inggris adalah novel. Alur cerita novel anak menceritakan dunia dan pemikiran anak-anak. Metode yang digunakan dalam penelitian ini adalah mengkaji bentuk tuturan imperatif dalam novel anak berbahasa Inggris Hello Universe karya Erin Entrada Kelly dengan kajian pragmatik. Objek atau data penelitian ini adalah tuturan imperatif struktural dan nonstruktural pada novel Hello Universe karya Erin Entrada Kelly. Teknik dalam pengumpulan data dilakukan dengan teknik simak dan catat bersumber dari novel. Analisis data menggunakan metode agih dan padan dengan teknik Bagi Unsur Langsung (BUL) dan Pilah Unsur Penentu (PUP) dengan daya pilah pragmatis, yaitu membaca kalimat imperatif novel Hello Universe, mengklasifikasikan tipe kalimat imperatif struktural, menganalisis data berdasarkan bentuk dan fungsi tuturan imperatif, dan melakukan penyimpulan hasil penelitian. Pengecekan keabsahan data dilakukan dengan membercheck dan uji pakar pragmatik. Berdasarkan hasil penelitian ditemukan bentuk tuturan bermakna imperatif yang terdiri atas kalimat deklaratif, kalimat interogatif, dan kalimat imperatif. Makna imperatif dapat ditemukan dalam kalimat imperatif nonstruktural yang berupa kalimat deklaratif dan interogatif. Penggunaan imperatif dalam novel ini lebih banyak menggunakan tuturan langsung karena percakapan pada situasi pertemanan anak-anak yang nonformal. Fungsi tuturan imperatif struktural banyak berfungsi sebagai perintah. Sementara itu, sebagian besar kalimat interogatif memiliki fungsi sebagai permintaan dan kalimat deklaratif sebagai fungsi saran.
\end{abstract}

Kata kunci: makna imperatif, struktural, nonstruktural, novel anak

\section{THE MEANING OF STRUCTURAL AND NONSTRUCTURAL IMPERATIVES IN THE ENGLISH CHILDREN'S NOVEL HELLO UNIVERSE BY ERIN ENTRADA KELLY}

\begin{abstract}
One of the literary works for children that can be used as a medium for learning English is novel. The children's novel tells the children's worlds and thoughts. The method used in this research is examine the imperative form of speech in the English children's novel Hello Universe by Erin Entrada Kelly with a pragmatic study. The object or data of this research is the imperative structural and non-structural speech in the novel. The technique of collecting data was done by
\end{abstract}


using the observation technique and noting technique from the novel. The data analysis used the distributional and identity method with the Segmenting Immediate Constituents technique and Dividing Key Factors technique with pragmatic competence-in-dividing technique, namely reading imperative sentences in the novel, classifying structural imperative sentence types, analyzing data based on the form and function of imperative speech, and summarize research results. The data validity was checked through membercheck and pragmatic expert test. Based on the research results, it was found that the form of utterance with imperative meaning consists of declarative sentences, interrogative sentences and imperative sentences. The meaning of the imperative can be found in non-structural imperative sentences in the form of declarative and interrogative sentences. The use of imperatives in this novel uses more direct speech because the conversation is in non-formal children's friendship situations. The structural imperative speech function is mostly a command. Meanwhile, the interrogative sentence mostly has a function as a request and declarative sentences mostly has a function as a suggestion.

Keywords: meaning imperative, structural, nonstructural, children's novel

\section{A. Pendahuluan}

Dalam kehidupan sehari-hari, manusia secara tidak sadar telah menggunakan tuturan imperatif untuk meminta maupun memerintah orang lain agar keinginannya dapat terpenuhi (Rofiq, 2016:243-244). Tuturan imperatif sering dijumpai, baik secara tulisan maupun lisan. Dalam penyampaiannya, tidak semua tuturan imperatif diekspresikan sesuai dengan struktur gramatikal imperatifnya (Fitriani, 2015:35). Tuturan imperatif dapat pula diekspresikan dengan bentuk nonstruktural atau nonimperatif. Makna tuturan imperatif tersebut sangat tergantung akan konteks situasi tutur percakapannya. Seperti pada contoh berikut.

(1) The sky is blue.

(2) Where are you?

(3) Clean the whiteboard!

Kalimat (1), (2), (3) di atas merupakan tuturan deklaratif, interogatif, dan imperatif berdasarkan fungsi konvesionalnya. Kalimat (1) dimaksudkan penutur untuk memberi tahu mitra tuturnya bahwa langit berwarna biru, kalimat (2) dimaksudkan penutur untuk bertanya mengenai keberadaan mitra tutur, dan kalimat (3) dimaksudkan penutur untuk memerintah mitra tutur agar membersihkan papan tulis. Namun, hal tersebut akan berubah jika dihadapkan dalam sebuah situasi yang berbeda.

(4) The office is too hot.

(5) Will you please stop? 
Kalimat (4) jika dituturkan oleh seorang bos kepada para karyawannya dalam situasi cuaca yang panas, maka bukan hanya memberi tahu kondisi kantor yang panas saja melainkan memerintahkan untuk menyalakan AC. Kalimat (5) jika dituturkan seorang murid kepada teman yang menjahilinya, maka kalimat (5) bukan hanya sekedar untuk bertanya, melainkan dia mulai kesal dengan tingkah temannya dan memerintahkannya agar berhenti untuk menjahilinya. Berdasarkan uraian tersebut, dapat dikemukakan bahwa tuturan bermakna imperatif dapat diekspresikan oleh penutur menggunakan kalimat deklaratif, interogatif, dan imperatif.

Bahasa Inggris merupakan bahasa internasional. Dengan demikian, bahasa Inggris menjadi bahasa yang banyak diminati untuk dipelajari oleh banyak orang. Salah satunya terdapat karya sastra untuk anak yang dapat dijadikan sebagai media pembelajaran bahasa Inggris, salah satunya karya sastra anak berbentuk novel. Novel diminati sebagai media pembelajaran bahasa Inggris karena terdapat kalimat-kalimat yang diambil berdasarkan dalam situasi percakapan nyata seharihari. Dalam buku anak sendiri, alur cerita lebih membicarakan dunia dan pemikiran anak-anak.

Menurut Winch (1991:19) dalam Nurgiyantoro (2004:108) mengatakan bahwa buku anak yang baik adalah buku yang diangkat berdasarkan kacamata anak. Hal tersebut dapat membuat anak lebih mudah memahami tentang dunia dan kehidupan. Anak berhak mendapatkan informasi tentang pengalaman kehidupan untuk mengembangkan imajinasinya. Menurut definisi Asosiasi Perpustakaan Amerika (dalam Alfu \& Yati, 2015:182) buku anak adalah buku yang sesuai dengan tingkat kemampuan membaca dan minat anak-anak dari kelompok umur tertentu atau tingkatan pendidikan, mulai prasekolah hingga kelas enam sekolah dasar. Oleh karena itu, cerita untuk anak yang baik harus berkaitan dengan dunia anak, dimana cerita dalam buku anak tersebut dapat merefleksikan pandangan anak tentang dunia. Cerita anak yang baik juga harus disajikan dengan bahasa yang jelas dan indah yang dikemas dengan alur peristiwa yang 
sistematis mulai dari pengenalan, konflik, komplikasi, klimaks, peleraian, dan penyelesaian (Noermanzah, 2017:30).

Leech (1993:33) dalam Putri \& Prabawa (2017:2) menyatakan bahwa pragmatik adalah studi tentang makna dalam hubungan dengan situasi ujar (speech situasions). Menurutnya pragmatik mempelajari bagaimana bahasa digunakan dalam komunikasi dan menyelidiki makna sebagai suatu yang abstrak. Sementara itu, menurut Yule (1996:3) dalam Baskoro (2014:76) mengatakan bahwa pragmatik merupakan studi tentang maksud penutur. Artinya, pragmatik mengkaji makna tuturan penutur dengan demikian menghasilkan komunikasi yang baik antara penutur dan mitra tutur.

Dalam penelitian ini tujuan peneliti ingin mengidentifikasi bentuk serta fungsi tuturan bermakna imperatif yang digunakan dalam novel anak berbahasa Inggris Hello Universe karya Erin Entrada Kelly. Peneliti memilih novel Hello Universe karya penulis Erin Entrada Kelly sebagai sumber data penelitian ini. Novel Hello Universe merupakan novel berbahasa Inggris untuk anak-anak rentang usia 8-12 tahun. Novel ini merupakan novel ketiga Erin yang diterbitkan pada tanggal 14 Maret 2017.

Dalam penelitian ini tujuan peneliti ingin mengidentifikasi tuturan kalimat bermakna imperatif yang digunakan dalam novel anak berbahasa Inggris Hello Universe karya Erin Entrada Kelly. Peneliti memilih novel Hello Universe karya penulis Erin Entrada Kelly sebagai sumber data penelitian fungsi imperatif. Novel Hello Universe merupakan novel berbahasa Inggris untuk anak-anak rentang usia 8-12 tahun. Novel ini merupakan novel ketiga Erin yang diterbitkan pada tanggal 14 Maret 2017. Novel ini juga memenangkan medali Newbery yaitu penghargaan terhadap buku anak-anak terbaik dari asosiasi perpustakaan Amerika pada tahun 2018. Erin Entrada Kelly merupakan penulis sastra anak-anak Filipina-Amerika. Buku-bukunya banyak menceritakan masalah, seperti bullying, membangun persahabatan, dan orang yang terasing. Dalam novel ini, terdapat banyak dialog imperatif antara anak-anak yang muncul dalam berbagai variasi fungsi. Oleh karena itu, penelitian ini bertujuan untuk mendeskripsikan bentuk dan fungsi 
kalimat yang bermakna imperatif dalam novel anak berbahasa Inggris Hello Universe karya Erin Entrada Kelly.

Ada beberapa penelitian yang relevan dengan penelitian ini antara lain dilakukan oleh Attaskhiiri (2017) dengan judul Analisis Bentuk dan Fungsi Tuturan Imperatif dalam Film La Rafle karya Rose Bosch. Penelitian ini bertujuan untuk meneliti bentuk dan fungsi tuturan imperatif yang terdapat dalam film berbahasa Prancis menggunakan teori Rahardi (2005) mengenai bentuk pragmatik imperatif dan fungsi pragmatik imperatif. Hasil dari penelitian tersebut ditemukan dua bentuk tuturan imperatif yaitu struktural dan nonstruktural, dan tujuh fungsi tuturan imperatif berupa permohonan, pemberian izin, ajakan, permintaan, perintah, anjuran, dan larangan. Selanjutnya, ada penelitian dari Nugraha (2019) dengan judul Maksud Imperatif dalam Modul Deklaratif dan Interogatif pada Interaksi Penjual dan Pembeli Secara Daring di H\&M Toys-Hobbies. Tujuan dari penelitian ini adalah mendeskripsikan maksud imperatif dalam modus deklaratif dan interogatif pada interaksi jual beli secara daring di H\&M Toys. Penelitian ini menggunakan teori wujud tuturan imperatif menurut Rahardi (2005). Hasil dari penelitian ini ditemukan tuturan yang mengandung makna imperatif dalam modus deklaratif, seperti suruhan, permintaan, permohonan, desakan, bujukan, imbauan, persilaan, anjuran, permintaan izin, mengizinkan, larangan, harapan, anjuran, dan "ngelulu". Sedangkan dalam modus interogatif yaitu imperatif suruhan, permintaan, permohonan, desakan, ajakan, dan permintaan izin.

Berdasarkan penjabaran di atas, penelitian ini memiliki kesamaan dan perbedaan dengan penelitian sebelumnya. Kesamaan penelitian ini berupa tuturan imperatif yang sama dengan penelitian Attaskhiiri (2017) dan Nugraha (2019) yaitu menganalisis bentuk dan maksud atau fungsi imperatif dalam modus imperatif nonstruktural. Namun, penelitian ini memiliki perbedaan dengan penelitian sebelumnya yaitu objek yang diteliti yaitu novel berbahasa Inggris untuk anakanak rentang usia 8-12 tahun. Teori dalam penelitian ini pun berbeda dengan penelitian sebelumnya. Penelitian ini tidak mengacu pada satu teori saja, tetapi 
menggunakan teori lain, yaitu tipe kalimat imperatif struktural, bentuk tuturan, dan fungsi imperatif.

\section{B. Metode Penelitian}

Metode penelitian ini menggunakan metode pragmatik dengan tujuan mengkaji bentuk tuturan imperatif dalam novel anak berbahasa Inggris Hello Universe karya Erin Entrada Kelly. Penelitian ini menggunakan pendekatan deskriptif untuk mendeskripsikan tipe kalimat impertif struktural, bentuk tuturan imperatif, dan fungsi tuturan bermakna imperatif yang terkandung dalam novel anak berbahasa Inggris Hello Universe karya Erin Entrada Kelly. Teknik pengumpulan data dilakukan dengan teknik simak dan catat, yaitu membaca dan menyimak novel Hello Universe secara berulang-ulang. Selanjutnya, dilakukan teknik catat yaitu mencatat tuturan yang bermakna imperatif dalam novel anak berbahasa Inggris berjudul Hello Universe karya Erin Entrada Kelly.

Dalam penelitian ini tahap analisis data menggunakan metode agih dan padan. Metode agih digunakan untuk menganalisis unsur dari bahasa itu sendiri, sedangkan metode padan sedangkan metode padan digunakan untuk menganalisis bahasa yang penentunya merupakan unsur-unsur diluar bahasa itu sendiri. Setelah itu, metode agih diwujudkan dengan teknik bagi unsur langsung (BUL). Hal ini dilakukan karena cara kerja teknik ini yaitu dengan membagi satuan lingual data menjadi beberapa bagian atau unsur. Setelah dianalisis dengan teknik BUL, data dianalisis menggunakan teknik lanjutan yaitu teknik baca markah. Pemarkah dapat disebut juga penanda. Pemarkahan menunjukkan kejatian satuan lingual atau identitas konstituen tertentu (Sudaryanto, 1993:95). Langkahlangkah yang dilakukan dalam menganalisis data yaitu: (1) membaca kalimat demi kalimat novel Hello Universe, (2) mengklasifikasikan berdasarkan bentuk tuturan imperatif, (3) menganalisis data yang telah diklasifikasi berdasarkan fungsi tuturan yang imperatif, dan (4) melakukan penyimpulan hasil penelitian.

Sementara itu, dalam uji keabsahan data digunakan cara membercheck dengan uji pakar pragmatik untuk mengecek hasil analisis berdasarkan dengan teori yang digunakan. Selanjutnya, hasil analisis data divalidasi oleh pakar 
pragmatik sehingga penelitian ini diharapkan dapat dipertanggungjawabkan keilmiahannya.

\section{Hasil Penelitian dan Pembahasan}

\section{Hasil Penelitian}

Pada novel Hello Universe ini ditemukan bentuk kalimat imperatif, interogatif, dan deklaratif yang bermakna imperatif. Peneliti menggunakan teori kombinasi dari Swan (1995:254) dalam Ariyanti (2017:20) dan Quirk dan Greenbaum (1973:200-202) dalam Wenzen (2016:6). Dengan demikian, didapatkan 10 tipe kalimat imperatif, yaitu tipe kalimat imperatif emphatic, negative, passive, with subject, without subject, question tag, let, word order, and/or, dan ditemukan pola baru yaitu pola kombinasi negative with subject dalam novel ini. Hasil dari analisis bentuk tuturan bermakna imperatif dapat dilihat pada Tabel 1.

Tabel 1. Bentuk Tuturan bermakna Imperatif dalam Novel Berbahasa Inggris Hello Universe karya Erin Entrada Kelly

\begin{tabular}{cc}
\hline Bentuk Tuturan Bermakna Imperatif & Jumlah \\
\hline Deklaratif & 44 \\
\hline Interogatif & 16 \\
\hline Imperatif & 87 \\
\hline Total & 147 \\
\hline
\end{tabular}

Berdasarkan tabel 1, terlihat bahwa bentuk tuturan yang dominan adalah tuturan imperatif struktural, sebanyak 87 kalimat. Tipe kalimat imperatif struktural yang paling banyak ditemukan adalah imperatif yang tidak memiliki subjek atau without subject.

Hornby (1976:193) dalam dalam Aditya \& Andayani (2015:121) menyatakan bahwa kalimat imperatif dapat diungkapkan dengan berbagai cara, yaitu command (kata kerja perintah/komando), invitation (undangan), request (permintaan), suggestion (saran), dan advice (nasehat). Di sisi lain menurut Drummand (1972: 23) dalam Aditya \& Andayani (2015:121) kalimat imperatif juga dapat digunakan 
untuk membuat prohibition (suatu larangan) untuk tidak melakukan sesuatu atau larangan oleh penutur kepada pendengar.

Tabel 2. Fungsi Tuturan Bermakna Imperatif dalam Novel Berbahasa Inggris Hello Universe Karya Erin Entrada Kelly

\begin{tabular}{|c|c|c|}
\hline \multirow{6}{*}{$\begin{array}{c}\text { Fungsi Kalimat } \\
\text { Imperatif }\end{array}$} & Request (Permintaan) & 10 \\
\hline & Command (Perintah) & 69 \\
\hline & Suggestion (Saran) & 34 \\
\hline & Prohibitions (Larangan) & 20 \\
\hline & Advice (Nasehat) & 11 \\
\hline & Invitation (Undangan) & 3 \\
\hline
\end{tabular}

Berdasarkan tabel 2, terlihat bahwa fungsi imperatif yang dominan adalah tuturan imperatif yang berfungsi sebagai commands sebanyak 69 kalimat.

\section{Pembahasan}

Berdasarkan data yang telah dianalisis pada novel Hello Universe karya Erin Entrada Kelly bahwa kalimat-kalimat dalam novel Hello Universe harus ditelaah dari segi bentuk tuturannya sebelum mendapatkan makna imperatif pragmatiknya. Selain itu, diperlukan peninjauan dari segi komponen tuturnya. Hal tersebut untuk melihat fungsi dari tuturan imperatif tersebut. Dilihat dari hasil penelitian di atas, kalimat imperatif yang banyak digunakan dalam novel Hello Universe adalah kalimat imperatif struktural. Hal tersebut menunjukkan bahwa penulis novel menggambarkan percakapan dalam dunia anak-anak yang cenderung nonformal. Dilihat dari pemilihan tipe kalimat imperatifnya yang tidak menggunakan subjek, hal tersebut menunjukkan bahwa tidak tampak kesantunan dalam situasi perbincangan anak-anak. Ketika anak-anak bertutur dengan orang yang sebayanya menjadikan jarak sosial mereka menjadi lebih dekat. Anak-anak lebih bebas dalam bertutur dan memberikan respons kepada mitra tuturnya sehingga tingkat formalitas komunikasi menurun.

Pada penelitian yang dilakukan Attaskhiiri (2017) menggunakan film berbahasa Prancis sebagai sumber penelitiannya, sehingga data yang diperoleh berbeda penelitian ini. Sementara itu, penelitian ini menggunakan teori dari 
Hornby (1976) yang menyebutkan terdapat enam fungsi pragmatik dalam bahasa Inggirs. Keenam fungsi tersebut terdapat dalam novel Hello Universe karya Erin Entrada Kelly. Sementara itu, pada penelitian Nugraha (2019) menggunakan data bahasa Indonesia dengan teori yang sama dengan penelitian Attaskhiiri (2017) yaitu teori Rahardi (2005). Persamaan dengan dua penelitian sebelumnya adalah fungsi yang paling dominan adalah fungsi command (perintah). Hal tersebut menunjukkan bahwa imperatif struktural lebih banyak digunakan dalam situasi percakapan.

Berdasarkan data yang telah dianalisis pada novel Hello Universe, peneliti memilih beberapa analisis data yang mewakili bentuk tuturan bermakna imperatif sebagai berikut.

(1) “Don't tell your brothers.” (hlm. 42)

(Jangan beritahu saudara-saudaramu.)

Tuturan (1) merupakan bentuk kalimat imperatif negative. Pemarkah dalam tuturan (1) tersebut adalah verba don't. Pola dari imperatif negative adalah don't+base form. Tuturan tersebut bertujuan untuk memerintahkan Virgilo untuk tidak memberitahu kepada saudaranya kalau neneknya lebih menyayangi dirinya. Fungsi dari kalimat imperatif ini adalah prohibitions (larangan). Sama halnya dengan bentuk imperatif struktural yang ditemukan dalam penelitian Nugraha (2019) pada bahasa Indonesia secara struktural kalimat imperatif bermakna larangan biasanya ditandai penanda lingual dengan kata "jangan".

(2) “Let's talk about your dreams." (hlm. 215)

(Mari kita bicarakan tentang mimpimu.)

Tuturan (2) termasuk ke dalam kalimat imperatif yang menggunakan let. Pemarkah tuturan (2) tersebut adalah penggunaan kata let. Pola imperatif let diikuti oleh infinitive tanpa to. Pada tuturan tersebut Kaori memerintahkan Valencia untuk menceritakan mimpi-mimpinya. Fungsi tuturan tersebut termasuk dalam fungsi imperatif suggestion (saran). Berbeda dengan penelitian Attaskhiiri (2017) bahwa kalimat anjuran atau saran ini diberikan oleh orang yang memiliki 
kehormatan dibandingkan mitra tutur. Dalam penelitian ini fungsi suggestion (saran) terjadi dalam perbincangan anak-anak yang sebaya.

Dalam novel hello universe juga ditemukan kalimat deklaratif dan interogatif yang memiliki makna imperatif, sebagai berikut.

\section{(3) 'I'm probably gonna die if you don't get me to a hospital or} something." (hlm. 296)

(Aku kemungkinan bisa mati jika kamu tidak membawaku ke rumah sakit atau semisalnya)

Tuturan (3) termasuk ke dalam kalimat deklaratif yang memiliki makna imperatif. Kalimat deklaratif memiliki ciri yaitu mengekspresikan sebuah pernyataan atau memberikan informasi kepada mitra tutur. Kalimat deklaratif bermakna imperatif pun ditemukan dalam penelitian Attaskhiiri (2017) yang mengatakan ciri dari kalimat tersebut terlihat dalam konstituen pembentuk tuturan, analisis dilanjutkan dengan teknik baca markah. Pemarkah yang digunakan berupa pemarkah artikel yang menyatakan ciri ketatabahasaan. Pemarkah pada tuturan tersebut yaitu tanda titik (.). Tuturan (3) merupakan kalimat deklaratif karena berisi pernyataan seorang tokoh bernama Chet yang suka membully teman-temannya. Tuturan ini berfungsi sebagai perintah karena situasi pada saat itu Chet telah digigit oleh seekor ular. Sehingga Chet yang panik lalu lalu memerintah Valencia secara tidak langsung untuk membawanya ke rumah sakit atau nyawanya tidak akan tertolong.

(4) “Can't you tell?” (hlm. 136)

(Bisakah kamu katakan?")

Pada chapter 14 ditemukan tuturan merupakan kalimat interogatif yang bermakna imperatif. Tuturan (4) ini mengindikasikan ke dalam kalimat interogatif karena sebagai sebuah pertanyaan dan diakhiri dengan (?). Dalam bahasa Inggris, fungsi request (permintaan) ditandai dengan penanda lingual please, do, would you, can you, atau will you. Sementara itu, dalam penelitian Nugraha (2019) bahwa dalam bahasa Indonesia kalimat interogatif yang bermakna imperatif ditandai dengan penanda lingual "tolong" atau frasa "minta". Pada tuturan (4) ini fungsi permintaan diujarkan oleh Kaori kepada adiknya Gen mengenai rasi-rasi 
bintang di langit. Secara tidak langsung Kaori meminta Gen untuk memberi tahu nama rasi bintang yang sedang dilihatnya.

\section{Simpulan}

Berdasarkan penelitian yang telah dilakukan, peneliti menemukan beberapa bentuk tuturan bermakna imperatif yang terdiri atas kalimat imperatif struktural dan nonstruktural pada novel Hello Universe karya Erin Entrada Kelly. Bentuk kalimat imperatif struktural yaitu imperatif negatif, imperatif dengan subjek, imperatif yang diikuti tanda tanya, imperatif word order, imperatif dengan let, imperatif dengan and/or, dan imperatif tanpa subjek. Melihat dari peristiwa atau karakter pada novel, penggunaan imperatif yang ada lebih dominan imperatif tanpa subjek. Melihat dari peristiwa atau karakter pada novel, penggunaan bentuk tuturan imperatif yang lebih dominan adalah bentuk imperatif yang sesuai dengan fungsinya atau struktural. Hal tersebut terjadi karena dialog dominan terjadi di antara tokoh anak-anak yang sebaya, dengan demikian tuturan yang digunakan pun merupakan tuturan langsung dan bukan dalam bentuk formal.

Selain itu, terdapat beberapa fungsi tuturan imperatif dalam novel Hello Universe antara lain command (kata kerja perintah/komando), invitation (undangan), request (permintaan), suggestion (saran), dan advice (nasehat). Dalam penggunaan fungsi tuturan imperatif struktural yang lebih dominan adalah fungsi command (perintah). Sementara itu, pada tuturan bermakna imperatif nonstruktural yaitu kalimat interogatif memiliki fungsi dominan sebagai fungsi request (permintaan) dan kalimat deklaratif sebagai fungsi suggestion (saran).

Banyaknya penggunaan kalimat imperatif struktural dengan fungsi command atau perintah menunjukkan bahwa kalimat imperatif dengan bentuk tuturan langsung banyak digunakan dalam percakapan sehari-hari. Dalam pembelajaran bahasa dan sastra, hasil penelitian ini dapat diimplikasikan sebagai contoh penggunaan tuturan imperatif saat berkomunikasi. Hal ini dapat digunakan untuk mengembangkan kemampuan speaking (berbicara) dan writing (menulis) bagi siswa maupun mahasiswa yang sedang belajar bahasa Inggris. Pengetahuan 
mengenai bentuk dan fungsi tuturan dapat juga menambah pembelajaran pragmatik dalam bahasa Inggris.

\section{Daftar Pustaka}

Aditya, S. E. \& Nike Andayani, N. (2015). An Analisis of Imperative Sentence on Medicine Product. Literary Criticism Journal, 2(2), https://jurnal.unived.ac.id/index.php/jlc/article/view/225

Alfu, N.L. \& Yati. (2015). Pengaruh Penggunaan Media Buku Cerita Terhadap Kemampuan Membaca Siswa Kelas IV Madrasah Ibtidaiyah di Banjarmasin. Mu'adalah: Jurnal Studi Gender dan Anak, 2(2). 174-187, doi:10.18592/jsga.v2i2.477.

Ariyanti TM, A. (2018). The Correlation Between Student's Mastery Of Imperative Sentence And Their Ability In Writing Procedure Text. (Doctoral Dissertation, lain Salatiga).

Attaskhiiri, M. (2017). Analisis Bentuk dan Fungsi Tuturan Imperatif dalam Film La Rafle Karya Rose Bosch. UNY-Fle, 6(1), 60-74.

Baskoro, B. S. (2014). Pragmatik dan Wacana Korupsi. Jurnal Humaniora, 26(1), 74-83.

Fitriani, R. S. (2015). Kesantunan Tuturan Imperatif Siswa SMK Muhammadiyah 2 Bandung: Kajian Pragmatik. Ranah: Jurnal Kajian Bahasa, 4(1), 35. doi:10.26499/rnh.v4i1.23

Noermanzah, N. (2017). Plot in a Collection of Short Stories "Sakinah Bersamamu" Works of Asma Nadia with Feminimism Analysis. Humanus, 16(1), 30. doi:10.24036/jh.v16i1.7015

Nugraha, R. R. W. (2019). Maksud Imperatif dalam Modul Deklaratif dan Interogatif pada Interaksi Penjual dan Pembeli Secara Daring di H\&M Toys-Hobbies. Skripsi, Universitas Sanata Dharma.

Nurgiyantoro, B. (2004). Sastra Anak: Persoalan Genre. Jurnal Humaniora, 16(2), 107-122.

Putri, A. T., \& Prabawa, A. H. (2017). Wujud Makna Pragmatik Tindak Tutur Imperatif Dalam Film Keluarga Cemara dan Implementasinya sebagai Bahan Ajar Bahasa Indonesia Kelas VIII SMP. (Doctoral dissertation, Universitas Muhammadiyah Surakarta). 
Rahardi, K. (2005). Pragmatik: Kesantunan Imperatif Bahasa Indonesia. Jakarta: Erlangga.

Rofiq, F. A. (2016). Analisa Redaksi Tindak Tutur Imperatif dalam Surat AlBaqarah. Kodifikasia, 9(1), 243-244. doi:10.21154/kodifikasia.v9i1.468

Sudaryanto. (1993). Metode dan Aneka Teknik Analisis Bahasa: Pengantar Penelitian Wahana Kebudayaan secara Linguistis. Yogyakarta: Duta Wacana University Press.

Wenzen, N. (2016). Kalimat Imperatif dalam Film Spy Karya Paul Feig Suatu Analisis Sintaksis. Jurnal Elektronik Fakultas Sastra Universitas Sam Ratulangi, 4(5). 